\title{
Expression of the cell to cell adhesion molecule, ALCAM, in breast cancer patients and the potential link with skeletal metastasis
}

\author{
SIMON R. DAVIES ${ }^{1}$, COLIN DENT $^{2}$, GARETH WATKINS $^{1}$, \\ JUDY A. KING ${ }^{3}$, KEFAH MOKBEL ${ }^{4}$ and WEN G. JIANG ${ }^{1}$

\begin{abstract}
Departments of ${ }^{1}$ Metastasis and Angiogenesis Research Group, ${ }^{2}$ Trauma and Orthopaedics, College of Medicine, Cardiff University, Cardiff, UK; ${ }^{3}$ Department of Pharmacology and Pathology, Center for Lung Biology, University of South Alabama, Mobile, AL, USA; ${ }^{4}$ Department of Surgery, St. George Hospital, London, UK
\end{abstract}

Received August 24, 2007; Accepted October 1, 2007

\begin{abstract}
The activated leukocyte cell adhesion molecule (ALCAM) is involved in cell migration and adhesion. Decreased levels of ALCAM expression in breast cancer tissue are known to correlate with poor prognosis. The current study specifically investigated the ALCAM expression in tumours which developed skeletal metastasis. Fresh frozen primary breast cancer tissues $(n=234)$ and non-neoplastic mammary tissue $(n=34)$ were used. The distribution and location of ALCAM was assessed using immunohistochemical methods and the level of ALCAM was determined using quantitative RT-PCR. The results were analysed against the clinical and pathological data. ALCAM staining was largely membranous and cytoplasmic in normal epithelial cells and is significantly stronger than in cancer cells $(p=0.023)$ and patients who develop skeletal metastasis $(\mathrm{p}=0.048)$. The ALCAM transcript levels were lowest in patients with skeletal metastasis $(\mathrm{p}=0.0048)$ but were also significantly lower in patients who developed local recurrence $(\mathrm{p}=0.040)$ and in those who died from breast cancer $(\mathrm{p}=0.0075)$. Patients with moderate and poor prognostic indices have a lower level than those with a good index ( $\mathrm{p}=0.05$ and $\mathrm{p}=0.0089$ respectively) and ER-positive tumours show a lower level than ERnegative $(\mathrm{p}=0.043)$. Ductal carcinomas, $86 \%$ of the cohort, have a similar pattern of changes with skeletal metastasis patients having significantly lower levels $(p=0.015)$. This study has, for the first time, shown that patients who develop skeletal metastasis tend to have the lowest levels of ALCAM
\end{abstract}

Correspondence to: Dr Simon Davies, Metastasis and Angiogenesis Research Group, Department of Surgery, University Hospital of Wales, Heath Park, Cardiff CF14 4XN, UK

E-mail: simondavies@doctors.org.uk

Key words: activated leukocyte cell adhesion molecule, breast cancer, skeletal metastasis transcripts in their breast cancers, a finding potentially useful for clinical practice.

\section{Introduction}

The breast is the most frequent site of cancer in women and ranks second to lung cancer in the number of deaths in women (1). It is generally accepted that there are a number of prognostic factors in breast cancer that significantly influence survival. These include the size of the primary breast tumour, the histological type, histological grade, presence or absence of regional/auxillary lymph node metastases, presence or absence of oestrogen and progesterone receptors and the presence or absence of distant metastases (2). It has been reported that the skeleton is one of the most common sites for distant metastases in breast cancer with the cumulative incidence at any time being $8.2 \%$ at 2 years and $27.3 \%$ at 10 years (3). There are classically 5 types of primary cancer that metastasize to the skeleton of which breast cancer is responsible for the greatest number [breast $35 \%$, prostate $30 \%$, bronchus $10 \%$, kidney $5 \%$, thyroid $2 \%$ and others $18 \%$ (4)]. There is a significantly poorer prognosis if skeletal metastasis occurs. The aim is to be able to identify which breast cancers will metastasize so treatment strategies and a more accurate prognosis can be delivered.

The activated leukocyte cell adhesion molecule (ALCAM) is a glycoprotein of the immunoglobulin superfamily. ALCAM has been identified in multiple species and has different names depending on the species and laboratory that described it: chicken neural adhesion molecule BEN/SC-1/DM-GRASP $(5,6,7)$, rat KG-CAM (8), fish neurolin (9), human melanoma metastasis clone D (MEMD) (10), mouse/human CD166 $(11,12)$, and rat HB2 $(13,14)$. ALCAM has 5 extracellular immunoglobulin domains (two $\mathrm{NH}_{2}$-terminal, membranedistal variable- $[\mathrm{V}]$-type folds and three membrane-proximal constant- [C2]-type immunoglobulin folds), a transmembrane region and a short cytoplasmic tail (15).

It was first implicated in cell migration when originally being mapped (11) and it has since been reported to be involved in homotypic/homophilic and heterotypic/ 
heterophilic (to CD6) adhesion (16). It has been studied in tumours before: malignant melanoma in which approximately half were found to have ALCAM positivity and the expression is seen in the vertical growth phase of melanoma (17) and prostate cancer in which the ALCAM expression was lost in high grade tumours (18), colorectal carcinoma (19) and oesophageal squamous cell carcinoma (20). ALCAM has also been reported to be involved in capillary tube formation (21) and in vessel invasion in cartilage in vitro (22).

Degen et al (10) were the first to look for the presence of ALCAM in breast carcinoma and performed Northern blot analysis of MEMD (a partner to ALCAM) mRNA and found expression in the MCF-7 mammary carcinoma cell line. Studies have more recently demonstrated ALCAM in resected breast tumours (23) and King et al reported a decreased level of the ALCAM expression correlating with nodal involvement, grade, TNM stage, poor prognostic index (NPI) and clinical outcome (local recurrence and death) (24). These findings have recently been substantiated by Jezierska et al who similarly concluded that low ALCAM concentrations correlated with an aggressive phenotype (25).

Although ALCAM has been identified as being associated with disease progression, there has been no investigation into whether the location of metastasis is linked to ALCAM. In the present study we evaluated the ALCAM expression in breast carcinoma using tissue from patients who have been followed for 10 years and have been studied extensively in our department $(24,26,27,28,29,30,31)$. Owing to the relatively small numbers of patients developing skeletal metastases we have increased our numbers by adding a second cohort of breast cancer patients. Our results suggest that a decreased ALCAM expression is of clinical significance in skeletal metastasis from ductal breast cancer.

\section{Materials and methods}

Materials. The RNA extraction kit and the RT kit were obtained from AbGene Ltd. (Surrey, UK). PCR primers were designed using Beacon Designer (Palo Alto, CA, USA) and synthesized by Invitrogen Ltd. (Paisley, UK). Molecular biology-grade agarose and the DNA ladder were from Invitrogen (Carlsbad, CA, USA). The master mix for routine PCR and quantitative PCR (Qabsolute) were from AbGene Ltd. Mouse monoclonal antibody ALCAM/CD166 (for immunohistochemistry) was obtained from Novocastra Laboratories (Newcastle upon Tyne, UK). Peroxidase conjugated anti-mouse antibodies were from Sigma (Poole, Dorset, UK) and a biotin universal kit was from Dako Ltd. (Carpinteria, CA, USA).

Cells and tissues. Primary breast cancer tissues $(n=234)$ and non-neoplastic mammary tissue (from the same mastectomy specimens) $(n=34)$ were collected with the approval of the local ethics committees in Cardiff and London and were stored at $-70^{\circ} \mathrm{C}$. Patients were routinely followed clinically after surgery and their details stored in a database. The median follow-up period was 120 months. Details of histology were obtained from pathology reports provided by an independent specialist pathologist using hematoxylin and eosin (H\&E)-stained frozen sections. The results are shown
Table I. Clinical and pathological information of the study cohort.

\begin{tabular}{|c|c|c|}
\hline Clinical information & $\begin{array}{l}\text { Entire } \\
\text { cohort }\end{array}$ & $\begin{array}{l}\text { Ductal } \\
\text { cancers }\end{array}$ \\
\hline \multicolumn{3}{|l|}{ Nodal status } \\
\hline Negative & 107 & 87 \\
\hline Positive & 105 & 102 \\
\hline \multicolumn{3}{|l|}{ Grade } \\
\hline Grade 1 & 35 & 24 \\
\hline Grade 2 & 78 & 57 \\
\hline Grade 3 & 108 & 105 \\
\hline \multicolumn{3}{|l|}{ Histology } \\
\hline Ductal & 190 & N/A \\
\hline Lobular & 11 & N/A \\
\hline Medullary & 1 & N/A \\
\hline Tubular & 2 & $\mathrm{~N} / \mathrm{A}$ \\
\hline Mucinous & 14 & N/A \\
\hline Other & 2 & N/A \\
\hline \multicolumn{3}{|l|}{ NPI staging } \\
\hline NPI 1 & 74 & 55 \\
\hline NPI 2 & 89 & 77 \\
\hline NPI 3 & 40 & 36 \\
\hline \multicolumn{3}{|l|}{ ER status } \\
\hline Negative & 107 & 90 \\
\hline Positive & 105 & 89 \\
\hline \multicolumn{3}{|l|}{ Bone metastasis } \\
\hline Negative & 222 & 173 \\
\hline Positive & 12 & 9 \\
\hline \multicolumn{3}{|l|}{ Clinical outcome } \\
\hline Disease-free & 159 & 127 \\
\hline Metastasis & 21 & 20 \\
\hline Local recurrence & 6 & 5 \\
\hline Died of breast cancer & 29 & 23 \\
\hline Died of unrelated disease & 7 & 7 \\
\hline
\end{tabular}

in Table I. Where normal non-neoplastic mammary tissues were used, no tumour cells were found in the sections. The results of the primary ductal breast cancer tissues $(n=190)$ are shown in Table I.

Tissue processing, RNA extraction and cDNA synthesis. Frozen sections of tissue were cut at a thickness of 5-10 $\mu \mathrm{m}$ and were kept for immunohistochemistry and routine histology. Other 15-20 $\mu \mathrm{m}$ sections were mixed and homogenized using a hand-held homogenizer, in ice-cold RNA extraction solution. The concentration of RNA was determined using a UV spectrophotometer. Reverse transcription was carried out using an RT kit with an anchored oligo dT primer supplied by AbGene and $1 \mu \mathrm{g}$ total RNA in a 96-well plate. The quality of cDNA was verified using $\beta$-actin primers (5'-caggaggttgaa ggactaaa-3' and 5'-gggatcagttttctttgtca-3'). 
Quantitative analysis of ALCAM transcript and protein. The level of ALCAM transcripts from the earlier prepared cDNA was determined using a real-time quantitative PCR, based on the Amplifluor ${ }^{\mathrm{TM}}$ technology (32), modified from a previously reported method (33). Briefly, pairs of PCR primers were similarly designed using the Beacon Designer software (version 2) (5'-caggaggttgaaggactaaa-3' and 5'-gggatcag ttttctttgtca-3'), but an additional sequence, known as the $\mathrm{Z}$ sequence (5'-actgaacctgaccgtaca-3'), which is complementary to the universal Z probe (30) (Intergen Inc., Livingston, UK), was added to one of the primers (ALCAMZr). A Taqman detection kit for $\beta$-actin was purchased from Perkin-Elmer (Surrey, UK). The reaction was carried out using the following: Hot-start Q-master mix (Abgene), 10 pmol specific forward primer, 1 pmol reverse primer that had the $\mathrm{Z}$ sequence, 10 pmol FAM-tagged probe (Intergen Inc.) and cDNA from 50 ng RNA. The reaction was carried out using IcyclerIQ ${ }^{\mathrm{TM}}$ (BioRad, Hemel Hempstead, UK), which is equipped with an optic unit that allows real-time detection of 96 reactions, using the following conditions: $94^{\circ} \mathrm{C}$ for $8 \mathrm{~min}$, then 38 cycles of $94^{\circ} \mathrm{C}$ for $15 \mathrm{sec}, 55^{\circ} \mathrm{C}$ for $20 \mathrm{sec}, 72^{\circ} \mathrm{C}$ for $40 \mathrm{sec}$ and finally $72^{\circ} \mathrm{C}$ for $10 \mathrm{~min}$. The levels of the transcripts were generated from a standard [purified plasmid with known quantity (34)] that was simultaneously amplified with the samples and which are presented as relative levels calculated from the internal standard. The epithelial content within the tumours was taken into account by normalizing ALCAM against cytokeratin 19 . The cytokeratin 19 forward and reverse primers were 5'caggtccgaggttactgac-3' and 5'-actgaacctgaccgtacacac tttctgccagtgtgtcttc-3', respectively.

Immunohistochemical staining. The procedure was similar to that previously reported, with minor modifications $(26,28)$. Briefly, the frozen sections of breast tumour and nonneoplastic breast tissue were cut at a thickness of $5 \mu \mathrm{m}$ using a cryostat. The sections were mounted on microscope slides, air-dried and then fixed in a mixture of $50 \%$ acetone and $50 \%$ methanol for $20 \mathrm{~min}$. The sections were then placed in a 'Menapath' autowash buffer for 5-10 min to rehydrate. Sections were incubated for $20 \mathrm{~min}$ in a horse serum blocking solution and probed with the primary antibody (1:50 dilution ALCAM) at room temperature for $1 \mathrm{~h}$. Following extensive washings, sections were incubated for $30 \mathrm{~min}$ in the secondary horse serum. Following washings, Avidin biotin complex (Vector Laboratories Ltd.) was then applied to the sections, followed by extensive washings. Diaminobenzidine chromogen (Vector Laboratories Ltd.) was then added to the sections, which were incubated in the dark for $5 \mathrm{~min}$. The sections were then dehydrated in ascending grades of methanol before clearing in xylene and mounting under a coverslip before initial photographs were taken. A rehydration process was then performed with descending grades of methanol before removing the coverslip and counterstaining in Mayer's hematoxylin for $1 \mathrm{~min}$. The process of dehydration and mounting was then repeated.

Staining intensity was semiquantified using a method established in our laboratory (35), which was modified and based on that reported by Fidler and colleagues (36). Briefly, gray-scale digitized images were imported into the Optimas software (Optimas 6.0, Optimus Corp., Bothell, WA, USA).
The intensity of the cell adhesion molecules was measured in two locations from randomly chosen cells: the cytoplasmic and the intercellular adhesion regions, where appropriate. Control staining (without primary antibody) was used for the extraction of the background staining. Intensity data were exported to Excel for statistical analysis and are presented here as the mean intensity of either the cytoplasmic region or membranous staining.

Statistical analysis. A statistical analysis of RNA transcript data was carried out using the Mann-Whitney U test. Furthermore, a statistical analysis of the immunohistochemical staining was carried out using the two-sided two-tailed t-test.

\section{Results}

Immunohistochemical staining. ALCAM staining was seen in normal epithelial cells of normal breast tissue and cancer cells in tissue in patients who went onto develop skeletal metastasis (Fig. 1A, B and C). Analysis of the staining intensity (Fig. 1D) shows that the cytoplasmic staining in normal breast tissue is significantly stronger than that in either the standard breast cancer tissue ( $\mathrm{p}=0.023$ ) or the breast cancer tissue from patients who went onto develop skeletal metastasis $(\mathrm{p}=0.048)$.

ALCAM expression in breast cancer and normal tissue. Fig. 2A shows that the number of ALCAM transcripts in breast cancer is lower than in the normal breast tissue. The results are not, however, statistically significant ( $\mathrm{p}=0.78$ ). It would be expected that the levels would have been significantly lower and a possible reason for the disparity may be that there is a difference in cellularity between breast tumour tissues and the normal breast tissues.

ALCAM expression in the cohort of breast cancer patients. It was previously reported by King et al (24) on a smaller cohort, that there were significantly lower levels of ALCAM transcripts in more aggressive tumours. In the larger cohort we found a similar pattern with significantly lower levels of ALCAM found in patients with a widely recognized indicator of poor prognosis: with metastasis, with recurrence and bone metastasis, poor prognostic index (NPI) and positive ER status. These results are shown in Figs. 2B, 3A and 4A.

The most noteworthy of the results above is the difference in the ALCAM transcript level for the different patient clinical outcomes which were identified during their follow-up. Fig. 2B shows lower transcript levels in the patients with complications of metastasis, local recurrence $(p=0.040)$, skeletal metastasis $(\mathrm{p}=0.0048)$ and death $(\mathrm{p}=0.0075)$. Looking specifically at the patients who went on to develop skeletal metastasis, we can see that these patients have the lowest levels of ALCAM of any of the patient groups. Although not statistically lower than the other complications of breast cancer (other metastases, local recurrence and death) it is the most statistically different from the patients who were disease-free $(\mathrm{p}=0.0048)$.

Figs. 3A and 4A show the differences in transcript levels when comparing patients with moderate and poor NPI prognosis to those with a good prognosis $(\mathrm{p}=0.05$ and $\mathrm{p}=0.0089$ respectively) and those with a positive ER status 

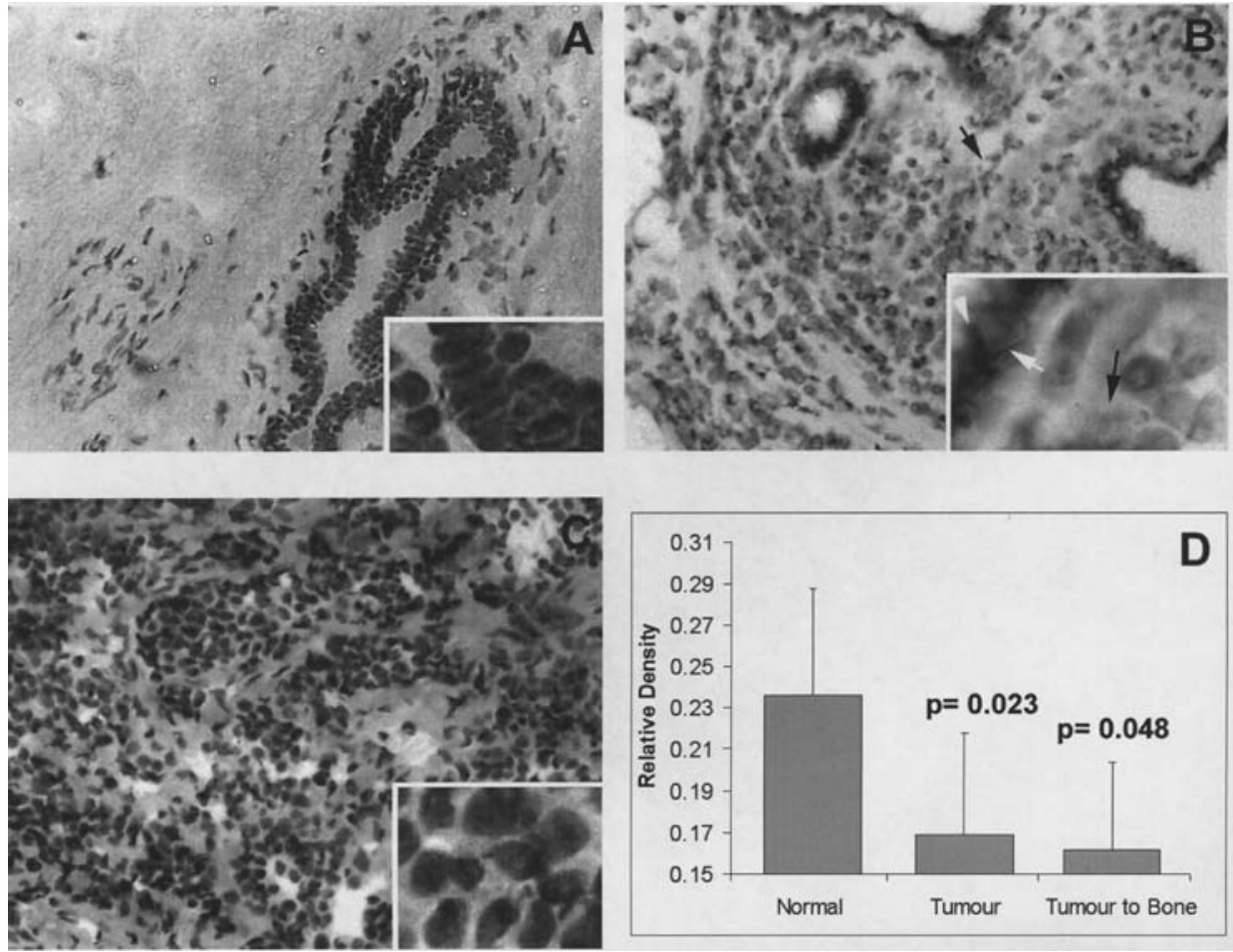

Figure 1. Immunohistochemical staining showing (A) normal tissue, (B) tissue from breast cancer patient (black arrows indicate cancer cells and white arrows indicate residue of normal tissue with staining at the intracellular junction), (C) tissue from breast cancer patient with skeletal metastasis and (D) analysis of staining intensity, shown at x100 magnification and x400 for the inserts.
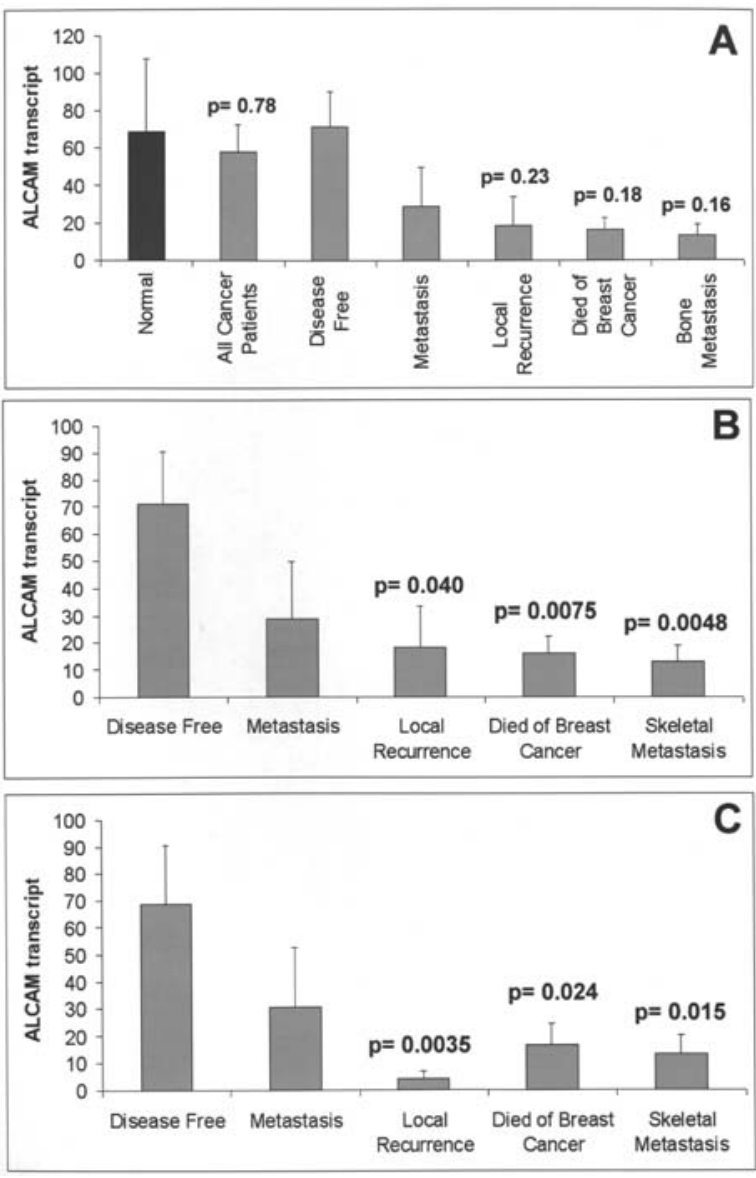

Figure 2. ALCAM transcript levels for the different patient clinical outcome groups (A) compared to normal patients, (B) disease-free patients and (C) in ductal carcinoma compared to disease-free patients. $(\mathrm{p}=0.043)$. Fig. 5A shows the difference in ALCAM transcript levels in patients with and without nodal involvement and although not significant, it does suggest a lower level in the node-positive patients $(\mathrm{p}=0.16)$.

ALCAM expression in ductal carcinoma. When subdividing the cancer groups the ductal carcinomas were the overwhelming subgroup (86\%). We have therefore re-analyzed the data and found the same pattern of differences. Again there is a significant difference in the ALCAM transcript level in each of the different clinical outcome settings (Fig. 2C). For local recurrence $(\mathrm{p}=0.0035)$, skeletal metastasis $(\mathrm{p}=0.015)$ and death $(\mathrm{p}=0.024)$ the transcript levels are less than the levels found in patients with no recurrence.

Figs. 3B, 4B and $5 \mathrm{~B}$ show the results of patients with: a poor NPI prognosis to those with a good prognosis $(\mathrm{p}=0.021)$, patients with a positive ER status to a negative status $(\mathrm{p}=0.05)$ and, although not significant, the trend that patients with a positive nodal status tend to have lower ALCAM transcript levels than patients with no positive nodes.

Although not looked at directly in this study it was notable that patients with an ER negative status who went on to develop skeletal metastasis had a significantly lower level $(p=0.0061)$ of ALCAM transcript than those who did not develop skeletal metastasis.

\section{Discussion}

It has previously been demonstrated that decreased ALCAM transcripts in the primary tumours correlated with nodal involvement, higher grade tumours, higher TNM stage, worse 

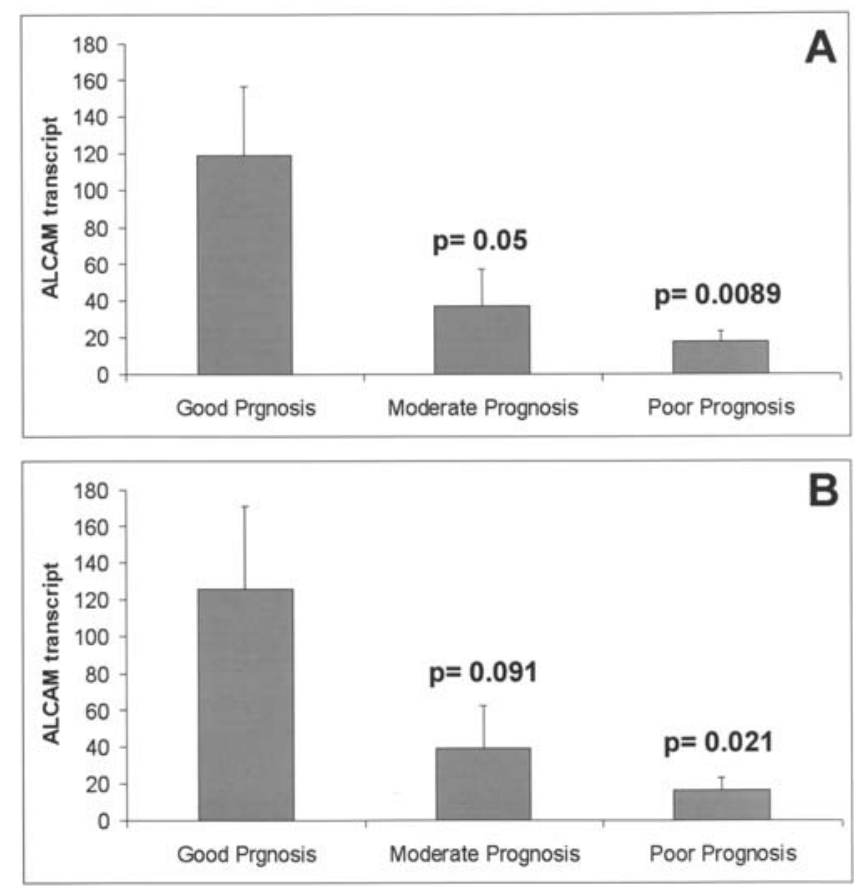

Figure 3. ALCAM transcript levels in prognostic groups defined by their NPI, (A) entire cohort and (B) ductal carcinomas.
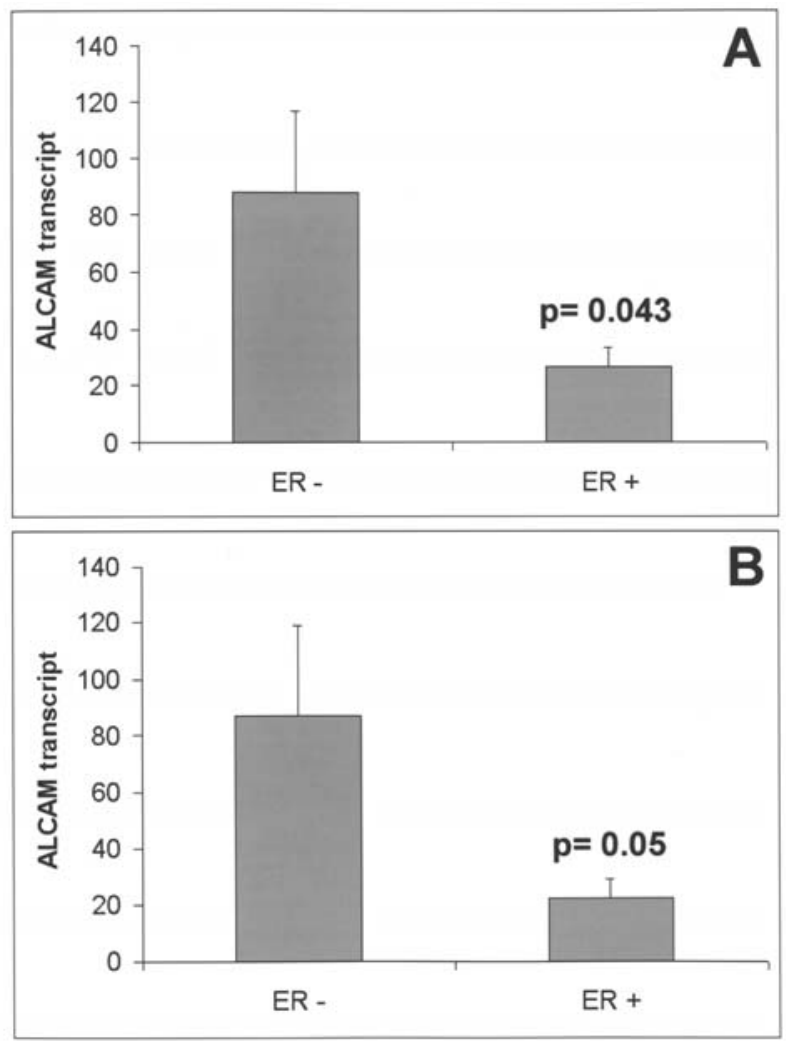

Figure 4. ALCAM transcript levels in prognostic groups defined by their oestrogen receptor (ER) status, (A) entire cohort and (B) ductal carcinomas.

NPI index, presence of local recurrence and death due to breast cancer (24). These data suggested that a decreased ALCAM expression in the primary tumour was of clinical
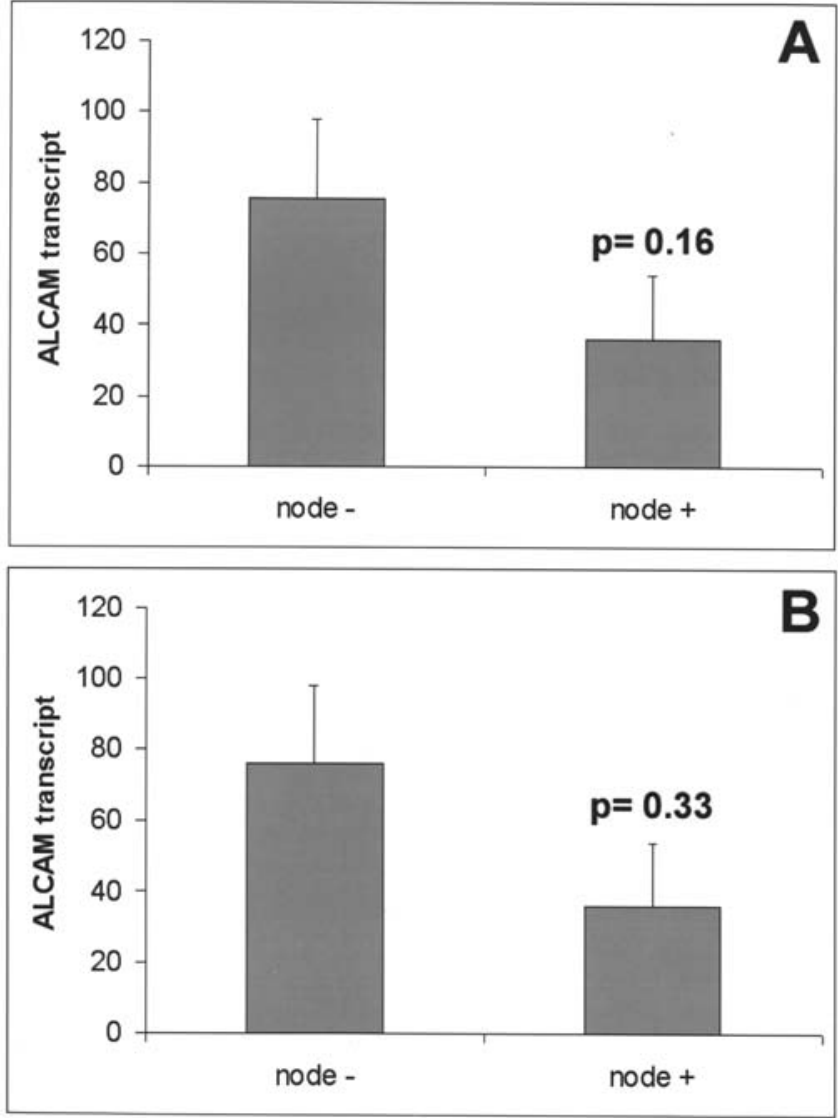

Figure 5. ALCAM transcript levels in prognostic groups defined by their nodal involvement, (A) entire cohort and (B) ductal carcinomas.

significance and that a reduced expression indicates a more aggressive phenotype and poor prognosis. In this analysis we used an expanded tumour cohort of 234 breast cancer patients to re-evaluate the previous findings and for the first time, specifically identified patients who went on to develop skeletal metastasis.

Normal ductal epithelial cells in breast tissue showed positivity to ALCAM in immunohistochemical stains (Fig. 1A, $\mathrm{B}$ and $\mathrm{C}$ ). This positivity was also seen in breast cancer tissue and in breast cancer tissue from patients who went on to develop skeletal metastasis. The level of staining was, however, significantly lower in the breast cancer tissues than that of normal ductal epithelial cells (Fig. 1D). Immunohistochemical staining of breast tissues alone with the antibody used would therefore not distinguish between benign and malignant cells using the method described in this study. Burkhardt and colleagues, however, found that there was a higher ALCAM expression in intraductal and invasive breast carcinomas than in normal breast tissue. They used the same antibody as used in this study, but at a different concentration and with a slightly different method (37). The established pathologic criteria for carcinoma, including the architecture, nuclear pleomorphism and mitotic counts, therefore have to be evaluated.

The level of ALCAM transcripts is lower in primary tumours compared to normal breast tissue from the same mastectomy specimens, although it was not statistically significant (Fig. 2A). This correlates well with the immuno- 
histochemical staining results, in that individual tumour cells stained more weakly than individual normal mammary epithelial cells (Fig. 1A, B and C). However, we would have expected a much lower result. There are a number of possible reasons for this discrepancy. There may be a difference in cellularity between breast tumour tissues and the normal breast tissues thereby giving an inappropriately raised transcript level in the breast tumours. The error may rest with a different epithelial/tumour cell content in different tumours and the possible contribution from infiltrating immune cells since haemopoietic stem cells and activated $\mathrm{T}$ lymphocytes express ALCAM (38-41). The cohort of normal breast tissue is also relatively small $(n=34)$ compared to the number in the breast cancer cohort $(n=234)$ thereby increasing the risk of statistical error.

The patients who went on to develop skeletal metastasis tended to have the lowest levels of ALCAM transcript out of all the different patient groups, lower even than those that died from the original breast cancer (Fig. 2B). When compared to the patients who were disease-free at follow-up, the ALCAM transcript levels were significantly lower $(\mathrm{p}=0.0048)$. The results were reproduced when looking at the sub-group of ductal carcinomas (Fig. 2C) with the ALCAM transcript level again being significantly lower $(\mathrm{p}=0.015)$.

The results gathered from this enlarged cohort confirmed the previous finding by King et al (25). It can be seen that there are lower levels of ALCAM transcripts in the patients who went on to develop metastasis and the level was statistically lower in patients with local recurrence $(\mathrm{p}=0.0040)$ or who died from the disease ( $\mathrm{p}=0.0075)$ (Fig. 2B).

The NPI (42) is a clinical parameter of prognosis which combines tumour size, lymph node stage and histological grade into a formula to determine prognostic groups. The group with $\mathrm{NPI}<3.4$ has the best prognosis, NPI $>5.4$ is associated with poor prognosis and NPI=3.4-5.4 has an intermediate prognosis. The scoring system has been validated in prospective studies (43) and is used in countries such as the UK (44). We demonstrated that patients with a moderate and poor prognosis have a significantly lower ALCAM transcript level than those patients with a good prognosis (moderate $\mathrm{p}=0.05$ and poor $\mathrm{p}=0.0089$ ).

A positive ER status for a patient is another widely recognized indicator of a poor prognosis and the ALCAM transcript levels were lower $(\mathrm{p}=0.043)$ in the positive group compared to the ER negative group. Although not statistically significant, the ALCAM level was lower in patients who were found to have a positive lymph node status $(\mathrm{p}=0.16)$.

This study also looked at the dominant cancer type subgroup of ductal carcinomas. Ductal cancers make up $86 \%$ of the entire cohort and the same pattern of lower ALCAM transcript levels in the patients with poor prognostic indicators was seen as it was in the cohort as a whole. There was a significantly lower level of ALCAM transcripts in the patients with a poor NPI prognosis compared to those with a good prognosis $(\mathrm{p}=0.021)$, lower levels in ER-positive patients $(\mathrm{p}=0.05)$ and lower levels in node-positive patients $(\mathrm{p}=0.33)$.

We hypothesize that the reduced expression of ALCAM, a molecule involved in cell adhesion, may allow the tumour cells to disaggregate and so enter the circulation and metastasize. This property was seen in other cell adhesion molecules such as E-cadherin (45-47). E-cadherin was demonstrated as having the ability to shed its cadherin extracellular domain, to move from the cell surface to the cytoplasm or from the cell-cell adhesion areas to other areas of the membrane and transcriptional abnormalities as a result of gene promoter hypermethylation (48). ALCAM was reported to co-localize with E-cadherin in epithelial cells (49) and it may have similar abilities.

In conclusion, ALCAM is a glycoprotein that is involved with cellular adhesion, proliferation and tumour progression. In breast carcinoma, decreased ALCAM transcripts in the primary tumours are synonymous with predictors of poor prognosis: higher TNM stage, worse NPI index, nodal involvement, the presence of local recurrence and death due to breast cancer. This study has for the first time demonstrated that the patients with the lowest levels of ALCAM transcripts have a possibility of developing skeletal metastasis. This study suggested that the level of the ALCAM expression in primary breast carcinoma has clinical significance and that a reduced expression indicates a more aggressive phenotype and poor prognosis. This fact could be used to provide patients with a more accurate prognosis and identify those who may benefit from enhanced monitoring and early medical and orthopaedic treatment.

\section{Acknowledgements}

The authors would like to thank Cancer Research Wales and Breast Cancer Hope Foundation for supporting this work.

\section{References}

1. American Cancer Society: Cancer Facts and Figures 2006. Atlanta, GA, 2006.

2. Fleming I, Cooper J, Henson D, Hutter R, Kennedy B, Murphy G, O'Sullivan B, Sobin L and Yarbro J: Breast. In: AJCC Cancer Staging Manual. 5th edition Lippincott-Raven, Philadelphia, pp171-178, 1997.

3. Colleoni M, O'Neill A, Goldhirsch A, Gelber RD, Bonetti M, Thürlimann B, Price KN, Castiglione-Gertsch M, Coates AS, Lindtner J, Collins J, Senn H-J, Cavalli F, Forbes J, Gudgeon A, Simoncini E, Cortes-Funes H, Veronesi A, Fey M and Rudenstam C-M: Identifying breast cancer patients at high risk for bone metastases. J Clin Oncol 18: 3925-3935, 2000.

4. Downey SE and Bundred NJ: Bone Metastases. In: Recent Advances in Surgery 19. 1st edition, Johnson CD (ed). Churchill Livingstone, Edinburgh, pp 109-128, 1996.

5. Pourquie O, Corbel C, Le Caer J-P, Rossier J and Le Douarin N: BEN: a surface glycoprotein of the immunoglobulin superfamily, is expressed in a variety of developing systems. Proc Natl Acad Sci USA 89: 5261-5265, 1992.

6. Tanaka H, Matsui T, Agata A, Tomura M, Kubota I, McFarland KC, Kohr B, Lee A, Phillips HS and Shelton DL: Molecular cloning and expression of a novel adhesion molecule, SC1. Neuron 7: 535-545, 1991.

7. Burns F, von Kannen S, Guy L, Raper J, Kamholz J and Chang S: DM-GRASP, a novel immunoglobulin superfamily axonal surface protein that supports neurite extension. Neuron 7: 209-220, 1991.

8. Peduzzi J, Irwin M and Geisert E: Distribution and characteristics of a $90 \mathrm{kDa}$ protein, KG-CAM in the rat CNS. Brain Res 640: 296-307, 1994.

9. Paschke K, Lottspeich F and Stuermer C: Neurolin, a cell surface glycoprotein on growing retinal axons in the goldfish visual systems, is re-expressed during retinal axonal regeneration. $\mathbf{J}$ Cell Biol 117: 863-875, 1992.

10. Degen W, van Kempen L, Gijzen E, van Groningen J, van Kooyk Y, Bloemers $\mathrm{H}$ and Swart GWM: MEMD, a new cell adhesion molecule in metastasizing human melanoma cell lines, is identical to ALCAM (activated leukocyte cell adhesion molecule). Am J Pathol 152: 805-813, 1998. 
11. Bowen MA, Patel DD, Li X, Modrell B, Malacko AR, Wang W-C, Marquardt H, Neubauer M, Pesando JM, Francke U, Haynes BF and Aruffo A: Cloning, mapping and characterization of activated leukocyte-cell adhesion molecule (ALCAM), a CD6 ligand. J Exp Med 181: 2213-2220, 1995

12. Bowen MA, Bajorath J, D'Egidio M, Whitney GS, Palmer D, Kobarg J, Starling GC, Siadak AW and Aruffo A: Characterization of mouse ALCAM (CD166): the CD6-binding domain is conserved in different homologs and mediates cross-species binding. Eur J Immunol 27: 1469-1478, 1997.

13. Kurata H, Matsumoto A, Fujiwara Y, Kondo K, Itakura H, Mitchell A and Fidge N: A candidate high-density lipoprotein (HDL) receptor, HB2, with possible multiple functions shows sequence homology with adhesion molecules. J Atheroscler Thromb 4: 112-117, 1998.

14. Matsumoto A, Mitchell A, Kurata H, Pyle L, Kondo K, Itakura H and Fidge N: Cloning and characterization of HB2, a candidate high-density lipoprotein receptor. Sequence homology with members of the immunoglobulin superfamily of membrane proteins. J Biol Chem 272: 16778-16782, 1997.

15. Swart GWM: Activated leukocyte cell adhesion molecule (CD 166/ALCAM): developmental and mechanistic aspects of cell clustering and cell migration. Eur J Cell Biol 81: 313-321 2002.

16. van Kempen LC, Nelissen JMDT, Degen WGJ, Torensma R, Weidle UH, Bloemers HPJ, Figdor CF and Swart GWM: Molecular basis for the homophilic activated leukocyte cell adhesion molecule (ALCAM)-ALCAM interaction. J Biol Chem 276: 25783-25790, 2001.

17. van Kempen LC, Meier F, Egeblad M, Kersten-Niessen MJ, Garbe C, Weidle UH, Van Muijen GN, Herlyn M, Bloemers HP and Swart GWM: Truncation of activated leukocyte cell adhesion molecule: a gateway to melanoma metastasis. J Invest Dermatol 122: 1293-1301, 2004.

18. Kristiansen G, Pilarsky C, Wissmann C, Stephan C, Weissbach L, Loy V, Loening S, Dietel M and Rosenthal A: ALCAM/CD166 is up-regulated in low-grade prostate cancer and progressively lost in high-grade lesions. Prostate 54: 34-43, 2003.

19. Weichert W, Knosel T, Bellach J, Dieal M and Kistianse G: ALCAM/CD166 is overexpressed in colorectal carcinoma and correlates with shortened patient survival. J Clin Pathol 1160-1164, 2004.

20. Verma A, Shukla NK, Deo SVS, Gupta SD and Ralham R: MEMD/ALCAM: A potential marker for tumour invasion and nodal metastasis in esophageal squamous cell carcinoma. Oncology 68: 463-470, 2005.

21. Ohneda O, Ohneda K, Arai F, Lee J, Miyamoto T, Fukushima Y, Dowbenko D, Lasky LA and Suda T: ALCAM (CD166): its role in hematopoietic and endothelial development. Blood 98: 2134-2142, 2001

22. Arai F, Ohneda O, Miyamoto T, Zhang X and Suda T: Mesenchymal stem cells in perichondrium express activated leukocyte cell adhesion molecule and participate in bone marrow formation. J Exp Med 195: 1549-1563, 2002.

23. King JA, Al-Mehdi A-B, Ofori-Acquah SF and Stevens T: Role of ALCAM in interaction of breast cancer metastases and the endothelium of the lung. FASEB J 18: 330, 2004.

24. King JA, Ofori-Acquah SF, Stevens T, Al-Mehdi AB, Fodstad O and Jiang WG: Activated leukocyte cell adhesion molecule in breast cancer: prognostic indicator. Breast Cancer Res 6: R478-R487, 2004.

25. Jezierska A, Olszewski WP, Pietruszkiewicz J, Olszewski W, Matysiak W and Motyl T: Activated leukocyte cell adhesion molecule (ALCAM) is associated with suppression of breast cancer cells invasion. Med Sci Monit 12: BR245-BR256, 2006.

26. Jiang WG, Douglas-Jones A and Mansel RE: Level of expression of lipoxygenases and cyclooxygenase- 2 in human breast cancer. Prostaglandins Leukot Essent Fatty Acids 69: 275-281, 2003

27. Jiang WG, Douglas-Jones A and Mansel RE: Expression of peroxisome-proliferator activated receptor-gamma (PPAR $\gamma$ ) and the PPARgamma co-activator, PGC-1 in human breast cancer correlates with clinical outcomes. Int J Cancer 106: 752-757, 2003.

28. Jiang WG, Watkins G, Lane J, Cunnick GH, Douglas-Jones A, Mokbel K and Mansel RE: Prognostic value of Rho GTPases and Rho guanine nucleotide dissociation inhibitors in human breast cancers. Clin Cancer Res 9: 6432-6440, 2003.

29. Parr C, Watkins G, Mansel RE and Jiang WG: The hepatocyte growth factor regulatory factors in human breast cancer. Clin Cancer Res 10: 202-211, 2004.
30. Al-Rawi MA, Rmali K, Watkins G, Mansel RE and Jiang WG Aberrant expression of interleukin-7 (IL-7) and its signaling complex in human breast cancer. Eur J Cancer 40: 494-502, 2004

31. Davies G, Cunnick GH, Mansel RE, Mason MD and Jiang WG Levels of expression of endothelial markers specific to tumourassociated endothelial cells and their correlation with prognosis in patients with breast cancer. Clin Exp Metastasis 21: 31-37, 2004

32. Nazarenko IA, Bhatnagar SK and Hohman RJ: A closed tube format for amplification and detection of DNA based on energy transfer. Nucleic Acids Res 25: 2516-2521, 1997

33. Somlyo AV, Bradshaw D, Ramos S, Murphy C, Myers CE and Somlyo AP: Rho-kinase inhibitor retards migration and in vivo dissemination of human prostate cancer cells. Biochem Biophys Res Commun 269: 652-659, 2000.

34. Cunnick GH, Jiang WG, Gomez KF and Mansel RE: Lymphangiogenesis quantification using quantitative PCR and breast cancer as a model. Biochem Biophys Res Commun 288: 1043-1046, 2001

35. Davies G, Jiang WG and Mason MD: Cell-cell adhesion molecules and signaling intermediates and their role in the invasive potential of prostate cancer cells. J Urol 163: 985-992, 2000.

36. Kuniyasu $\mathrm{H}$, Ellis LM, Evans DB, Abbruzzese JL, Fenoglio CJ, Bucana CD, Cleary KR, Tahara E and Fidler IJ: Relative expression of E-cadherin and type IV collagenase genes predicts disease outcome in patients with resectable pancreatic carcinoma. Clin Cancer Res 5: 25-33, 1999.

37. Burkhardt M, Mayordomo E, Winzer K-J, Fritzsche F, Gansukh T, Pahl S, Weichert W, Denkert C, Guski H, Dietel M and Kristiansen G: Cytoplasmic overexpression of ALCAM is prognostic of disease progression in breast cancer. J Clin Pathol 59: 403-409, 2006.

38. Uchida N, Yang Z, Combs J, Pourquie O, Nguyen M, Ramanathan R, Fu J, Welply A, Chen S, Weddell G, Sharma AK, Leiby KR, Karagogeos D, Hill B, Humeau L, Stallcup WB, Hoffman R, Tsukamoto AS, Gearing DP and Peault B: The characterization, molecule cloning, and expression of a novel hematopoietic cell antigen from $\mathrm{CD} 34^{+}$human bone marrow cells. Blood 89: 2706-2716, 1997.

39. Stephan J-P, Bald L, Roberts PE, Lee J, Gu Q and Mather JP: Distribution and function of the adhesion molecule BEN during rat development. Dev Biol 212: 264-277, 1999.

40. Corbel C, Bluestein HG, Pourquie O, Vaigot P' and Le Douarin NM: An antigen expressed by avian neuronal cells is also expressed by activated T lymphocytes. Cell Immunol 141: 99-110, 1992.

41. Corbel C, Pourquie O, Cormier F, Vaigot P and Le Douarin NM: BEN/SC1/DM-GRASP, a homophilic adhesion molecule, is required for in vitro myeloid colony formation by avian hemopoietic progenitors. Proc Natl Acad Sci USA 93: 2844-2849, 1996.

42. Ellis I, Pinder S, Lee A and Elston C: Tumours of the Breast. In: Diagnostic Histopathology of Tumours. 2nd edition, Fletcher $\mathrm{C}$ (ed). Churchill Livingstone, New York, pp865-930, 2000.

43. Galea MH, Blamey RW, Elston CE and Ellis IO: The Nottingham prognostic index in primary breast cancer. Breast Cancer Res Treat 22: 207-219, 1992.

44. Miller W, Ellis I, Sainsbury J and Dixon J: ABC of breast diseases. Prognostic factors. Br J Med 309: 1573-1576, 1994.

45. Moll R, Mitze M, Frixen UH and Birchmeier W: Differential loss of E-cadherin expression in infiltrating ductal and lobular breast carcinomas. Am J Pathol 143: 1731-1742, 1993.

46. Goldstein NS, Bassi D, Watts JC, Layfield LJ, Yaziji H and Gown AM: E-cadherin reactivity of 95 noninvasive ductal and lobular lesions of the breast. Implications for the interpretation of problematic lesions. Am J Clin Pathol 115: 534-542, 2001.

47. Acs G, Lawton TJ, Rebbeck TR, LiVolsi VA and Zhang PJ: Differential expression of E-cadherin in lobular and ductal neoplasms of the breast and its biologic and diagnostic implications. Am J Clin Pathol 115: 85-98, 2001.

48. Jiang WG: E-cadherin and its associated protein catenins, cancer invasion and metastasis. Br J Surg 83: 437-446, 1996.

49. Tomita K, van Bokhoven A, Jansen CFJ, Bussemakers MJG and Schalken JA: Coordinate recruitment of E-cadherin and ALCAM to cell-cell contacts by a-catenin. Biochem Biophys Res Commun 267: 870-874, 2000. 